\title{
Using inquiry-based interventions to improve secondary students' interest in science and technology
}

\author{
Patrice Potvin ${ }^{1}$, Abdelkrim Hasni ${ }^{2}$, and Ousmane Sy ${ }^{1}$ \\ ${ }^{1}$ Département de didactique, Université du Québec à Montréal, Montréal, Canada \\ ${ }^{2}$ Facultéd'éducation, Université de Sherbrooke, Sherbrooke, Canada \\ For correspondence: potvin.patrice@uqam.ca
}

\begin{abstract}
Nine secondary school teachers participated in a five-day training program where they developed inquiry-based pedagogical interventions for their science classes. Student interest and self-concept in school science and technology were measured before and after the interventions. Increases in interest and self-concept were compared with the results obtained from control groups. Results show a significant increase interest of moderate magnitude compared with the control condition, but no effect on self-concept. Our interpretation supports the use of inquiry-based interventions for science classes but also presents some of the challenges faced when developing them.
\end{abstract}

Keywords: Inquiry-based, interest, teacher training.

\section{Inquiry-based learning in sciences classes}

Inquiry-based learning is usually referred to as processes by which one comes to construct a rational understanding of the world and to communicate it to others using scientific concepts and statements. Such processes are often described in terms of adaptable phases or sequences of rationally driven operations that will hopefully lead to convincing arguments about objects or phenomena or how they behave. In this sense, inquiry-based learning confounds with the everyday work of scientists in the context of research. But inquiry-based learning also refers to learning in science classes at any level. In this case, inquiry-based learning is presumed to be triggered by inquiry-based teaching, where teachers encourage students to use scientific methods to solve scientific problems. Some versions of this kind of teaching extend to engineering (technological) processes where students not only strive to bring answers (or elements of answers) to scientific questions but also develop technological solutions or objects to satisfy identified needs.

A classic example of inquiry-based learning would be a teacher who asks his students to design and implement an experimental protocol to study the impact of certain factors on plant growth and then analyze the results and prepare a formal presentation of the results that were recorded during the realisation of the protocol. However, inquiry-based methods are not just about designing experiments. A geology-inspired observation-based protocol, for instance, could also qualify provided it is systematic and logic-based and aims to convince based on facts.

The amount of guidance provided to students can vary considerably, depending on the students' level of autonomy and previous knowledge. This issue seems to be at the heart of many of the challenges of implementing inquiry-based teaching in classrooms. On the one hand, too much guidance cancels out some of the best virtues (increased autonomy, problem-solving skills, scientific competence, learning by error, conceptualization, etc.). On the other hand, too little guidance can 
hinder learning because it overlooks fundamental and well documented cognitive constraints, like cognitive load (Kirschner, Sweller, \& Clark, 2006). In fact, evidence from research on different forms of guidance, including worked examples, has shown that students with guided instruction perform better on tests and sometimes even on problem-solving tasks than students with less guidance (p. 80). Yet inquiry-based teaching and guidance are not necessarily contradictory. Guidance can be embedded in inquiry-based teaching efforts and has even recently been considered as "pivotal to successful inquiry-based learning." (Lazonder \& Harmsen, 2016)

The impacts of inquiry-based teaching/learning on science and technology students

Yet inquiry-based teaching has long been considered a very promising and possibly rich approach by many researchers. In 2010, Minner et al. (2010) analyzed the impact of inquiry-based instruction on conceptual learning in 138 studies and concluded that it had a "clear, positive trend" (p. 474) compared with more passive teaching techniques. In 2012, Furtak et al. (2012), in a meta-analysis of 37 studies, reached a similar conclusion, while stressing the importance of guidance. Several other individual studies also reported convergent results (Geier et al., 2008).

Most of these studies focused on performance and "affective" outcomes, such as attitudes (Ergül et al., 2011; Gibson \& Chase, 2002; Wolf \& Fraser, 2008), engagement (Roche, O'Neill, and Prendergast, 2016), and confidence (Gormally, Brickman, Hallar, and Armstrong, 2009). All reported generally positive results. In their systematic review on interest, motivation, and attitude towards science and technology, Potvin and Hasni (2014b)argued that most of the articles considered (11 of the 17 articles), and that investigated the links between affective constructs and inquiry-based teaching methods, also reported positive outcomes and that none of the articles recorded negative results.

These rather encouraging results clearly suggest that inquiry-based teaching could be beneficial for learning and affect (providing certain circumstances, like minimal guidance) but that successfully implementing it in science classes remains marginal in most schools despite being recommended by many national and state curricula and even with considerable teacher-training efforts (Lee, Heart, Cuevas, \& Ennders, 2004; Wee, Shepardson, Fast, \& Harbor, 2007), especially with novice teachers (Luft, 2001). We must therefore consider the obstacles and difficulties that most likely limit its advent.

The challenges of bringing inquiry-based teaching to science classes

According to Keys and Bryan (2001, p. 636) "we have little knowledge of teachers' views about the goals and purposes of inquiry, the processes by which they carry it out, or their motivation for undertaking a more complex and often difficult to manage form of instruction." Clues can however be found in studies that were conducted on the challenges of implementing inquiry and through lists of recommendations (Brown \& Melear, 2006).

The first type of challenge to successful implementation is the understanding that teachers have of inquiry-based learning and its possible effects on students. For example, even though it is often presented a posteriori as a sequential process, inquiry-based learning is actually a non-linear activity that involves multiple retroactive loops and constant adjustments. But if teachers have never fully experienced this method themselves (like as scientists), it is possible that they think it is more "recipelike" - or a mere "verification-of-previously-presented-knowledge"-activity. "[T]eachers can be challenged in enacting authentic science tasks if they are not familiar with the practices of scientists and have never participated in authentic scientific activity themselves"' (Harris \& Rooks, 2010, p. 234). Brick house has already argued that teachers who have a more contemporary and accurate understanding of science tend to use a more problem-based approach to teaching (Brickhouse, 1990). Another example is when teachers believe that hypotheses are similar to simple "guesses". They might also sometimes reduce inquiry-based protocols to experimental protocols or confuse them with simple manipulative activities. The confusion between "hands-on" and "hands- and mind-on" 
approaches has been at the core of countless teacher training efforts because of the fundamentally different effects that they have. For example, manipulative activities have been argued to generate less interest than inquiry-based activities where students are able to make choices-and assume at least partial responsibility - in the resolution (Potvin \& Hasni, 2014b).

The second type of challenge is with regard to curricular considerations and classroom management, which become more difficult with inquiry-based teaching. Harris and Rooks argue that learning through inquiry is a very different way of learning for students, and therefore "places higher demands on students in terms of participation, personal responsibility for learning, and intellectual effort" (Harris \& Rooks, 2010, p. 232). It therefore changes how teaching is planned and changes interactions with students. Citing Crawford (2000), Harris and Rooks (2010) go on to argue that inquiry-based instruction requires a high level of pedagogical content knowledge, including a broad understanding of the nature of science and the complexities of coaching, mentoring, and collaborating with students. In fact, inquiry-based learning suggests that interactions between teachers will be more open and less guided than in ordinary settings and "following lesson descriptions step-by-step may not directly translate to success in inquiry classrooms" (p. 233).

Pervasive management of science ideas also requires ongoing and active assessment of students' thinking and ideas during instruction. This can be challenging when students are engaged in investigations with classmates and teachers are faced with managing multiple groups of students simultaneously.(Harris \& Rooks, 2010, p. 235)

Therefore, "[s]imply holding beliefs about the benefits of inquiry-based practices is not always sufficient to implement them in the classroom" (Brown \& Melear, 2006, p. 939). However, while it appears rather easy to change teachers' established beliefs with training (Bhattacharyya, Volk, \& Lumpe, 2009; Brown \& Melear, 2006; Harris \& Rooks, 2010; Lee et al., 2004; Luft, 2001), it remains difficult to change their practices. This is why "[a] viable strategy is to get teachers engaged in authentic inquiry-based research science experiences themselves" (Brown \& Melear, 2006, p. 940). It is therefore understandable that an attempt to evaluate the merits of implementing inquiry-based learning should first confirm the quality of the interventions through authentic and intensive inquirybased training that involves real-life tests.

\section{Research question}

Given the importance of inquiry-based teaching/learning in science education, its potential to improve learning and interest in science, and the challenges of implementing inquiry-based teaching, the research question here becomes "Do inquiry-based teaching interventions improve secondary students' interest in science and technology?" We chose to focus on interest instead of learning to give the teachers a choice of scientific topics. This research is also part of the CRIJEST research program aimed at improving student interest in science and technology.

In this study, the idea of "interest" generally refers to the connection between a subject and an object. More particularly, Hidi and Renninger (2006) define interest as "a psychological state that, in later phases of development, is also a predisposition to reengage content that applies to in-school and outof-school learning and to young and old alike" (p. 111). Self-concept will here be seen as "how a student views his or her academic ability when compared with other students" (Cockley, 2000, p. 149). 


\section{Methodology}

\section{Participants}

The study involved nine volunteer secondary teachers and 378 volunteer students from 22 different classes. The teachers were selected based on their interest in a teacher training initiative organized by the Research Chair on student's interest for science and technology (CRIJEST). In order to participate in the study, teachers had to teach one or more science classes to regular students in Grades 5 to 10. The training program (see the Procedure section for details) also included a research component with pre- and post-tests for students. Parental and student consent was therefore obtained. This consent was the only criteria used to select students.

\section{Instrument}

We used an adapted version of the general CRIJEST questionnaire, which tests interest, motivation, self-concept, and other subconstructs. For the purposes of this research and to answer the research question, we used the "interest in science and technology at school" subconstruct, which is tested with six items (Cronbach's $\alpha=0.89$ ) such as "I look forward to upcoming activities in S\&T"; "School science and technology are boring" (reversed); "We should spend more time doing science in school;" and "If I had a choice, I wouldn't go to S\&T course anymore" (reversed). We also used the "school S\&T self-concept" construct, which is also tested with six items (Cronbach's $\alpha=0.82$ ) such as "Compared to all the other students, I consider myself (good) at S\&T" or "Compared to my friends, I understand S\&T... (easily)". This subconstruct was included because it sheds light on how interest develops but also because it helps test the possible effects of implementing new teaching methods. For example, previous CRIJEST research efforts (Potvin \& Hasni, 2016) reported occasional drops in self-concept, possibly due to an increase in teachers' demands when implementing new ways of teaching. It was suggested that when demands increase, students feel more powerless. The complete version of the test and all questions is available in previous publications (Hasni \& Potvin, 2015a, $2015 b)$. The same questionnaire was used for the pre- and post-tests, both with the experimental and control groups. Variations were calculated and the observed differences between the two groups were analyzed.

\section{Procedure}

The interventions lasted between five to ten periods of approximately 75 minutes each and were designed by the participating teachers. The teachers attended a five-day training program where they learned about previous studies that had positive outcomes, the effects of inquiry-based interventions, the definition and properties of interventions that qualify as such,and the possible misconceptions (about inquiry-) sometimes observed among teachers who attempt to include these kinds of interventions in their practice.

For example, inquiry-based interventions were presented as situated problems that have meaning to students and allow them to question their understanding of related phenomena. They were also presented as challenges with a reasonable level of difficulty and that must be resolved using a rational sequence of events (including formulating a hypothesis, performing a procedure, and analyzing/interpreting data) and that will ultimately result in a reasoning based on facts, etc. For possible misconceptions, inquiry-based teaching methods innovations were presented as not to be confounded with exclusively experimental designs or mere manipulations or mere verification-ofpreviously-taught-knowledge processes, etc. Examples were provided.

With the help of their school board's guidance counsellor and university science professors, they then selected a segment of their practice that had the potential to be enhanced with inquiry-based characteristics. For example, a sequence about tropisms could be turned into a "learning situation" 
where children are asked to experimentally test how certain variables affect the growth and behaviour of real plants.

The teachers were given five days (separated by an average of two weeks) to develop their "enhanced" intervention with support and supervision from the counsellors and university professors who ensured that the interventions were as consistent as possible. They also determined a basis of comparison for the results. Since each teacher taught more than one class, they identified classes that would not use the new intervention but where the topic would be taught "as usual." These students, as well as those in the experimental group, were tested (pre-test). The interventions were then carried out and all students were tested immediately afterwards (post-test).

\section{Analysis}

The gains associated to experimental treatments were determined by calculating the differences between the pre- and post-test for both constructs studied and for both the experimental and control groups. This design choice was an attempt to obtain the best comparison possible. The topic being taught was therefore well controlled; although we are well aware that the analysis cannot guarantee that the students populating the compared groups were initially equivalent or that both kinds of treatments were entirely equal (except for their inquiry-based component). However the initial state of interest was controlled because all students (in both conditions) were pre-tested. Also, since the research question concentrates essentially on interest gains, this automatically corrects- because it includes- the initial state of interest.

\section{Results}

Table 1 provides an overview of the sample.

Table 1. Descriptive statistics

\begin{tabular}{lc}
\hline Total number of participants & 378 \\
Percentage of boys & $48 \%$ \\
Number of teachers involved & 9 \\
Participants per teacher (mean) & 42 \\
Number of classes involved & 22 \\
\hline
\end{tabular}

Interest in science and technology at school

Table 2 presents the results for performed t-test on "Interest in science and technology at school" increases in both groups. About half of the total number of students was considered in this analysis because not all of the questions were used with every student (in order to shorten the test [this analysis is part of a larger project]). All answers used for this analysis were however equally and randomly distributed among all participants.

Table 2. "Interest in science and technology at school" increases

\begin{tabular}{lcccccc}
\hline \multicolumn{1}{c}{ Group } & $N$ & $M$ & SD & $\begin{array}{c}\text { Std. error } \\
\text { mean }\end{array}$ & Sig. (2-tailed) & $\theta$ \\
\hline Experimental & 78 & -.00513 & .17776 & .02013 & $.005^{* *}$ & 0.506 \\
Control & 60 & -.09056 & .16887 & .02180 & & \\
\hline
\end{tabular}

Note: ${ }^{*} p<=0.05,{ }^{* *} p<=0.005$ 
The results presented in Table 2 suggest that the intervention had a positive and statistically significant effect compared with equivalent contexts where the interventions were not implemented. The effect size between the two treatments can be considered as medium, according to Cohen's standards (Cohen, 1988).

\section{School SET self-concept}

Table 3 presents the results for the t-test on "Interest in school science and technology" increases in both groups. It includes results from all participants who gave all valid answers for the considered analysis. If only one answer was missing, for instance, the participant's data was not considered. This is why the $\mathrm{N}$ total used in this analysis is not the same as the $\mathrm{N}$ total for the entire experiment.

Table 3. "School science and technology self-concept" increases

\begin{tabular}{lcccccc}
\hline \multicolumn{1}{c}{ Group } & $N$ & $M$ & $S D$ & $\begin{array}{c}\text { Std. error } \\
\text { mean }\end{array}$ & Sig. (2-tailed) & $\theta$ \\
\hline Experimental & 146 & -.00714 & .13049 & .01080 & 0.866 & -0.020 \\
Control & 137 & -.00974 & .12816 & .01095 & & \\
\hline
\end{tabular}

The results presented in Table 3 do not allow us to record any difference between the two treatments in terms of self-concept. The thresholds for significance and for detection of a minimal effect size have not been reached.

\section{Discussion}

In this article, we described an attempt to improve student interest in school science and technology using inquiry-based teaching interventions. For this study, teachers developed and administered five to ten 75-minute interventions to students in experimental groups. To ensure that the interventions qualified as "inquiry-based," the teachers agreed to participate in a five-day "training and development" program, and to have their work observed and constructively criticized by their peers, guidance counsellors, and university professors. Measures of interest and self-concept were taken in pre- and post-tests with both the experimental and control groups.

Results show a decrease in all measures during the total intervention period. These results coincide with observations from other contexts that use the same questionnaire. In fact, decreases are generally observed between the pre- and post-tests. This can be due to the habituation effect, or to the "normal" decrease in interest noted at the secondary school level (Potvin \& Hasni, 2014a) regardless of the interventions(Brouillette, Potvin, \& Samson, 2016; Potvin \& Hasni, 2016).This "questionnaire effect" suggests that including a comparison basis, like a control group, is essential for the interpretation of increases or decreases in interest.

In our design, gains were reported in both the experimental and control groups. We were therefore able to focus on comparing variations instead of variations due to other effects. A control group, however, does not prevent the results from being impacted by the novelty effect. Out-of-the-ordinary activities have been known to generate increases in learning and affective constructs, as is the case of learning from media (Clark, 1983). In our experiment, it is possible that the inquiry-based interventions were different enough from what our participants usually experience to have such an effect. However, since the interventions were not limited to a "touch-and-go" experiences of a few 
hours, but lasted a minimum of five periods, and sometimes as long as a month and a half, it is not unreasonable to think that the novelty effect was not present as much.

Nevertheless, our results suggest that the effect on interest in school science and technology was significantly higher with the experimental groups than with the control groups, and that this effect was of a moderate magnitude, which in an educational context can be considered as surpassing teacher effects (Hattie, 2009) and therefore should be recommended. This encouraging result coincides with other research efforts that showed positive outcomes of inquiry-based instruction in science on affective constructs (Ergül et al., 2011; Gibson \& Chase, 2002; Gormally et al., 2009; Potvin \& Hasni, 2014b; Roche et al., 2016; Wolf \& Fraser, 2008). We also believe that since constructs such as motivation, attitude and interest are closely linked to learning outcomes (Cavas, 2011; Reid \& Skryabina, 2002; Singh, Granville, \& Dika, 2002) (and especially with "critical thinking" (Hattie, 2009, p. 208)), our interventions should also produce increased learning.

No significant differences between the experimental and control groups were reported for the "Science and technology self-concept." This suggests that, at the end of the experiment, students did not feel more or less competent than they did in the beginning. The same results were obtained with the control group. This can be explained in part by the fact that the items often referred to other students, such as "Compared to all the other students, I consider myself (good) at S\&T." If students' absolute changes were felt (by students) as similar for all, than it should not be surprising that the relative evolution be stationary. But this result can also be seen as an indication that expectations were similar in both groups. In fact, self-concept has often been seen to change when expectations vary, and especially when students feel as though they have disappointed authority figures (Patrick \& Gibbs, 2012), like parents or teachers. If we apply this interpretation, we could argue that it is possible to improve interest even if expectations remain the same, which is rather encouraging for teachers who are considering implementing inquiry-based interventions.

Developing our interventions was challenging for the teachers and experts involved. Bear in mind that the five days was deemed necessary-initially by the organizers of the training and then later by the teachers who confirmed that developing the interventions would not have possible "if it had not been for all this time they benefited from." The conscious and constant efforts required to develop good inquiry-based interventions and avoid possible deviations due to misconceptions (about inquiry-)were also considerable. Some teachers admitted that, even though they were proud of their final pedagogical product, the development stages were at times a "headache." Given that pedagogical and field expertise were required simultaneously-and sometimes in confrontationthroughout the entire project, it is important to bear in mind that the final interventions proposed were reasonable compromises, even though they were inspired by evidence-based considerations. Compromises were made on several levels. For instance, steps were sometimes skipped in the inquiry-based processes, and students were given hints when they got stuck. This shows that teachers feel it is important to offer minimal guidance (Lazonder \& Harmsen, 2016) and is a reminder that pedagogical development is complex and sensitive to the context and must be more like an adventure than merely applying a pure method. We believe that the results are rather encouraging and in line with other findings. We therefore believe that all evidence points to inquiry-based learning/teaching having the potential to improve student interest in school science and technology.

\section{Acknowledgements}

We would like to thank all the teachers who participated in (and worked on) this and other CRIJEST studies. Special thanks to the Montreal, Rivière-du-Nord, Hautes-Rivières, Grandes-Seigneuries, and Marie-Victor in school boards for their financial support and help organizing this project. We would also like to thank François Thibault, Jean-Philippe Bolduc, Marie-Hélène Bruyère, Amélia Darsigny, 
Cynthia Paré, Chloé Lemay-Dagenais, Guillaume Malenfant-Robichaud, Kamal Achachi, and Olivier Laforest for their precious help with the data input and analysis.

\section{References}

Bhattacharyya, S., Volk, T., \& Lumpe, A. (2009). The influence of an extensive inquiry-based field experience on pre-service elementary student teachers' science teaching beliefs. Journal of Science Teacher Education, 20, 199-218. doi:10.1007/s10972-009-9129-8

Brickhouse, N. W. (1990). Teachers'beliefs about the nature of science and their relationship to classroom practice. Journal of Teacher Education, 41(3), 53-62. doi:10.1177/002248719004100307

Brouillette, N., Potvin, P., \& Samson, G. (2016). Effet d'activités exploitant la démarche de conception technologique sur l'intérêt des élèves à l'égard de la science et de la technologie. Paper presented at the 84thcongress of the Acfas, Universityof Quebec at Montreal, Quebec.

Brown, S. L., \& Melear, C. T. (2006). Investigation of secondary science teachers' beliefs and practices after authentic inquirybased experiences. Journal of Research in Science Teaching, 43(9), 938-962. doi:10.1002/tea.20110

Cavas, P. (2011). Factors affecting the motivation of Turkish primary students for science learning. Science education international, 22(1), 31-42.

Clark, R. E. (1983). Reconsidering research on learning from media. Review of Educational Research,53, 445-459.

Cockley, K. (2000). An investigation of academic self-concept and its relationship to academic achievement in African American college students. Journal of Black Psychology, 26(2), 148-164.

Cohen, J. (1988). Statistical power analysis for the behavioral sciences (second ed.): Routledge.

Crawford, B. A. (2000). Embracing the essence of inquiry: new roles for science teachers. Journal of Research in Science Teaching, 37(9), 916-937.

Ergül, R., Simskeli, Y., Calis, S., Ozdilek, Z., Gocmencelebi, S., \& Sanli, M. (2011). The effects of inquiry-based science teaching on elementary school students' science process skills and science attitudes. Bulgarian Journal of Science and Education Policy, 5(1), 48-66.

Furtak, E. M., Seidel, T., Iverson, H., \& Briggs, D. C. (2012). Experimental and quasi-experimenal studies of inquiry-based science teaching: A meta-analysis. Review of Educational Research, 82(3), 300-329. doi:10.3102/0034654312457206

Geier, R., Blumenfeld, P. C., Marx, R. W., Krajcik, J. S., Fishman, B., Soloway, E., \&Clay-Chambers, J. (2008). Standardized test outcomes for students engaged in inquiry-based science curricula in the context of urban reform. Journal of Research in Science Teaching, 45(8), 922-923. doi:10.1002/tea.20248

Gibson, H. L., \& Chase, C. (2002). Longitudinal impact of an inquiry-based science program on middle school students' attitudes toward science. Science Education, 86(5), 693-705. doi:10.1002/sce.10039

Gormally, C., Brickman, P., Hallar, B., \& Armstrong, N. (2009). Effects of inquiry-based learning on students' science literacy skills and confidence. International Journal for the Scholarship of Teaching and Learning, 3(2), 1-22. doi:10.20429/ijsotl.2009.030216

Harris, C. J., \& Rooks, D. L. (2010). Managing inquiry-based science: challenges in enacting complex science instruction in elementary and middle school classrooms. Journal of Science Teacher Education, 21(2), 227-240. doi:10.1007/s10972-0099172-5

Hasni, A., \& Potvin, P. (2015a). L'intérêt pour les sciences et la technologie à l'école: Résultats d'une enquête auprès d'élèves du primaire et du secondaire au Québec. Retrieved from Montréal:

Hasni, A., \& Potvin, P. (2015b). Student's interest in science and technology and its relationships with teaching methods, family context and self-efficacy. International Journal of Environmental and Science Education, 10(3), 337-366. doi:10.12973/ijese.2015.249a

Hattie, J. (2009). Visible learning: A synthesis of over 800 meta-analyses relating to achievement. NewYork, NY: Routledge.

Hidi, S., \& Renninger, K. A. (2006). The four-phase model of interest development. Educational Psychologist, 41(2), 111-127.

Keys, C. W., \& Bryan, L. A. (2001). Co-constructing inquiry-based science with teachers: Essential research for lasting reform. Journal of Research in Science Teaching, 38(6), 631-645. doi:10.1002/tea.1023

Kirschner, P. A., Sweller, J., \& Clark, R. E. (2006). Why minimal guidance during instruction does not work: An analysis of the failure of constructivist, discovery, problem-based, experiential, and inquiry-based teaching. Educational Psychologist, 41(2), 75-86.

Lazonder, A. W., \& Harmsen, R. (2016). Meta-analysis of inquiry-based learning: Effects of guidance. Review of Educational Research, 86(3), 681-718. doi:10.3102/0034654315627366

Lee, O., Heart, J. E., Cuevas, P., \& Enders, C. (2004). Professional development in inquiry-based science for elementary teachers of diverse student groups. Journal of Research in Science Teaching, 41(10), 1021-1043. doi:10.1002/tea.20037

Luft, J. A. (2001). Changing inquiry practices and beliefs: The impact of an inquiry-based professional development programme on beginning and experienced secondary science teachers. International Journal of Science Education, 23(5), 517-534. doi:10.1080/09500690121307

Minner, D. D., Levy, A. J., \& Century, J. (2010). Inquiry-based science instruction-What is it and does it matter? Results from a research synthesis years 1984 to 2002. Journal of Research in Science Teaching, 47(4), 474-496. doi:10.1002/tea.20347

Patrick, R., B., \& Gibbs, J. C. (2012). Inductive discipline, parental expression of disappointed expectations, and moral identity in adolescence. Journal of Youth and Adolescence, 41(8), 973-983. doi:10.1007/s10964-011-9698-7 
Potvin, P., \& Hasni, A. (2014a). Analysis of the decline in interest towards school science and technology from Grades 5 through 11. Journal of Science Education and Technology, 23(6), 784-802. doi:10.1007/s10956-014-9512-x

Potvin, P., \& Hasni, A. (2014b). Interest, motivation and attitude towards science and technology at K-12 levels: A systematic review of 12 years of educational research. Studies in Science Education, 50(1), 85-129. doi:10.1080/03057267.2014.881626

Potvin, P., \& Hasni, A. (2016). Une CAP qui s'inspire des résultats de recherche et qui en produit dans le but de favoriser l'intérêt des élèves à l'égard des sciences et de la technologie. Paper presented at the 84th ACFAS Conference, Université du Québec à Montréal, Québec.

Reid, N., \& Skryabina, E. A. (2002). Attitudes towards physics. Research in Science \& Technological Education, 20(1), 67-81.

Roche, J., O'Neill, A., \& Prendergast, M. (2016). An inquiry-based learning intervention to support post-primary engagement with science, technology, engineering and mathematics. European Journal od Science and Mathematics Education, 4(4), 431439.

Singh, K., Granville, M., \& Dika, S. (2002). Mathematics and science achievement: Effects of motivation, interest, and academic engagement. TheJournal of Educational Research, 95(6), 323-332.

Wee, B., Shepardson, D., Fast, J., \& Harbor, J. (2007). Teaching and learning about inquiry: Insights and challenges in professional development. Journal of Science Teacher Education, 18(1), 63-89. doi:doi:10.1007/s10972-006-9031-6

Wolf, S. J., \& Fraser, B. J. (2008). Learning environment, attitudes and achievement among middle-school science students using inquiry-based laboratory activities. Research in Science Education, 38(3), 321-341. doi:10.1007/s11165-007-9052-y 